\title{
INDIVIDUALISMO E PARTIDARISMO EM DOZE ESTADOS BRASILEIROS
}

\section{Carlos Ranulfo Melo}

\section{Introdução}

Este texto explora a relação entre deputados e partidos tendo como referencial empírico os representantes eleitos em 2006 para as Assembleias Legislativas em doze estados brasileiros: Rio Grande do Sul, Santa Catarina, São Paulo, Rio de Janeiro, Minas Gerais, Bahia, Pernambuco, Ceará, Pará, Tocantins, Goiás e Mato Grosso. A base de dados pertence ao projeto "Trajetórias, perfis e padrōes de interação de legisladores estaduais em doze unidades da Federação", conduzido por pesquisadores do Centro de Estudos Legislativos do DCP/UFMG. ${ }^{1}$

O ponto de partida para a análise é a opinião dos legisladores entrevistados. O objetivo do texto é explicar a variação encontrada quando se analisa o perfil partidário dos deputados. Evidentemente, as afirmações que aqui serão feitas são válidas apenas Artigo recebido em março/2010

Aprovado em setembro/2010 para o universo pesquisado. A primeira hipótese a ser verificada é a de que os deputados têm perfil mais nitidamente partidário nos estados onde o sistema partidário se encontra mais institucionalizado. Tal hipótese parte da noção de que no Brasil deve-se levar a sério a existência de uma dimensão de caráter horizontal (Mair e Bardi, 2009), referida à organização federativa, ao se analisar o sistema partidário. Os 27 subsistemas partidários brasileiros além de não serem "cópias" do sistema federal, apresentam grande variação, tanto no que se refere a quais são os partidos relevantes, como no que tange ao padrão de interação estabelecido (quando existe) entre eles.

A segunda linha de explicação remete às características dos deputados eleitos. A partir dos dados disponíveis no questionário foram testadas as hipóteses de que os deputados apresentam perfil mais partidário quando: a) mais tempo estiverem filiados a seus partidos; b) forem eleitos por par- 
tidos situados à esquerda do espectro partidário; c) se posicionarem de forma progressista em relação a temas como aborto, união civil de homossexuais, descriminalização de drogas, pena de morte e proibição do uso de armas; d) apresentarem menor tendência a um mandato de tipo particularista; e) declararem filiação religiosa menos conservadora; f) não pertencerem a famílias com tradição política; g) possuírem maior experiência legislativa; h) apresentarem menor renda e se dedicarem exclusivamente à atividade legislativa.

$\mathrm{O}$ artigo está organizado da seguinte forma. $\mathrm{Na}$ próxima seção, depois de uma breve contextualização da relação entre deputados e partidos no Brasil, é apresentada uma medida que procura classificar os deputados de acordo com seu perfil partidário, o "índice de partidarismo". Explica-se como se chegou a tal índice e qual sua variação. A terceira parte do artigo é dedicada aos sistemas partidários nos estados estudados. A partir de um conjunto de indicadores chega-se a um índice que, assim se espera, permite classificar os doze subsistemas partidários de acordo com uma das dimensōes da institucionalização - a estabilidade da competição eleitoral. $\mathrm{Na}$ quarta seção são apresentadas as hipóteses que buscam vincular determinadas características dos deputados à sua posição no índice de partidarismo. A quinta apresenta o modelo de regressão com o conjunto das variáveis independentes indicadas e discute os resultados. ${ }^{2}$

\section{Partidos e deputados}

A relação entre os políticos e os partidos brasileiros sempre foi motivo de controvérsia. Para uma parcela da literatura internacional (Mainwaring, 1991, 1993; Sartori, 1996; Cavarozzi e Casullo, 2003; Ames, 2003) o Brasil certamente poderia ser caracterizado com um país de políticos "sem partido". Por outro lado, a literatura nacional, e em especial aquela que tem se dedicado à área de estudos legislativos a partir dos trabalhos de Figueiredo e Limongi (1999), aponta para um comportamento disciplinado dos deputados no interior do processo legislativo.

$\mathrm{Na}$ verdade, no Brasil tanto é possível encontrar trajetórias políticas nas quais as diversas legen- das disponíveis no mercado eleitoral são ou foram utilizadas ao sabor da conjuntura, como também sobram exemplos de lideranças que construíram sua carreira por dentro de um mesmo partido. E é justamente esta variação que aqui se pretende explicar para o conjunto de estados selecionados.

As razóes pelas quais políticos "sem partido" são facilmente identificáveis entre nós podem ser apontadas sem maiores problemas. $\mathrm{O}$ país atravessou o chamado "século de Michels", a época de ouro das organizações partidárias, sem experimentar nada que se assemelhasse ao que Bernard Manin (1995), em sua tipologia dos governos representativos, chamou de "democracia de partido". Este tipo de governo só foi possível nos países onde os partidos chegaram a desempenhar papel relevante na mobilização e na incorporação dos indivíduos à condição de cidadania e onde, na esteira de tal processo, criaram extensas redes de apoio e fortes laços de identidade entre o eleitorado. A história brasileira, pelo contrário, registra poucos momentos em que os partidos tenham sido protagonistas de escolhas cruciais - a começar pelo fato, evidente, de que desde meados do século XIX até os anos de 1980 o país experimentou tantas formações partidárias quantas foram as mudanças de regime político.

Pode-se argumentar, e é verdade, que o atual sistema partidário terá tempo pela frente e que a sequência de eleições e, em especial, a dinâmica das disputas presidenciais vêm permitindo que o sistema adquira estabilidade e consolide uma estrutura de competição moderada (Melo, 2007). É certo também que os partidos controlam recursos importantes no cenário eleitoral, como o tempo de TV e o Fundo Partidário (Miranda, 2008; Campos, 2009), além de, como têm mostrado diversos autores (Figueiredo e Limongi, 1999 e 2002; Amorim Neto, 2000; Santos 2003; Inácio 2006) estruturam o jogo político em um nicho crucial: o Congresso Nacional.

Mas isso não anula o fato de que o "tempo" do atual sistema transcorrerá em um contexto em que os processos referidos - de mobilização e incorporação política nas democracias - já foram realizados e onde um novo fator, a mídia, torna possível o acesso dos políticos aos eleitores sem que estes tenham que necessariamente investir na construção de um 
partido ou de uma imagem partidária. Mais ainda, ao que tudo indica a competição política no país continuará se desenvolvendo no interior de uma estrutura de incentivos - materializada no sistema de lista aberta - que torna a competição eleitoral uma disputa entre indivíduos e estimula a priorização de estratégias que favorecem a criação de laços entre os candidatos e os eleitores, bem como a afirmação de atributos pessoais em relação aos do partido. Isso significa que embora possam ser computados ganhos no que se refere à estabilidade, o atual sistema partidário continuará operando em um contexto onde é muito pouco provável que uma parcela expressiva dos eleitores passe a se identificar de forma mais consistente com os partidos e a utilizá-los como referência básica para suas escolhas eleitorais. Em poucas palavras, o espaço para a construção de carreiras políticas marcadamente individualistas não é algo que vá diminuir com o tempo. Pelo contrário, tais carreiras continuarão a conviver com aquelas em que o partido é a referência indiscutível.

No presente estudo, para se chegar a uma medida da maior ou menor inclinação partidária dos deputados foram utilizadas quatro perguntas do questionário aplicado nas doze assembleias. As questôes foram as seguintes:

- Q.16 - Quanto à lista de candidatos para deputados e vereadores, qual o (a) sr(a) acredita ser o tipo mais adequado para o Brasil? 1. Lista aberta; 2. Lista fechada; 3. Outro tipo de lista. Qual?

- Q.30 - Na última eleição, qual foi o fator mais importante para conseguir apoio político-eleitoral de prefeitos e vereadores? E em segundo lugar? 1. Suas relaçôes pessoais ou familiares com prefeitos e/ou vereadores. 2. Suas relaçôes partidárias. 3. A intermediação de lideranças locais. 4. A ocupação prévia do cargo de prefeito em um município importante. 5. A realização de obras na região, em outras ocasiōes. 6. O seu apoio à campanha deles, quando eles foram candidatos.

- Q.61 - Quando há um conflito entre os interesses dos eleitores de sua região e as posições de seu partido, como o(a) Sr.(a) costuma votar? 1. Sempre com o partido; 2 . Sempre de acordo com os interesses dos eleitores de sua região.
- Q.63 - Quando um deputado, eleito por determinado partido, decide se desvincular deste partido, o que o(a) sr(a) acha que o deputado deve fazer? 1. Conservar sua cadeira e se integrar a outra bancada; 2. Renunciar à sua cadeira para que outro membro do partido assuma.

As quatro questões foram tratadas como variáveis dummy, sendo que o valor (0) significava uma posição de caráter mais individualista e o valor (1), uma posição de caráter partidário. Na pergunta 16 foi necessário classificar as respostas dos deputados que assinalaram "outro tipo de lista". Neste caso, os deputados foram convidados a explicitar sua opção. Quando isso apontou no sentido de uma lista pré-ordenada e flexível ou de uma lista fechada no contexto de um sistema eleitoral de tipo alemão, a resposta foi classificada como indicando comportamento mais partidário (1). No caso da questão de número 30 não existia uma contraposição entre as alternativas propostas aos deputados, mas foi possível destacar aqueles que assinalaram "as relações partidárias" em primeiro ou segundo lugar; as demais respostas foram agrupadas como (0).

$\mathrm{O}$ índice foi construído somando as respostas dadas (0 ou 1) por cada deputado. No entanto foi preciso lidar com o fato de que cerca de oitenta deputados declararam não ter recebido apoio de prefeitos ou vereadores em sua eleição (Q. 30). Optou-se por fazer uma ponderação, generalizando o procedimento de modo a valer para todas as questôes. Em outras palavras, foram considerados todos os casos em que os deputados responderam pelo menos três das quatro questôes. A soma obtida com as respostas foi dividida pelo total de questôes respondidas. Dessa forma, chegou-se a sete valores: 0,$0 ; 0,25 ; 0,33 ; 0,50$; 0,$67 ; 0,75$ e $1,0(0,25$ correspondendo a um ponto em quatro questões; 0,33 correspondendo a um ponto em três e assim sucessivamente). Posteriormente os valores foram reagrupados da seguinte maneira: 0,0 $=0 ; 0,25$ e $0,33=1 ; 0,5$ e $0,67=2 ; 0,75$ e $1,00=3$.

Ao fim e ao cabo, foi possível chegar a um índice de partidarismo com variação de 0 (perfil menos partidário) a 3 (perfil mais partidário). A Tabela 1 mostra a distribuição do índice em termos percentuais nos estados analisados, bem como o valor médio alcançado em cada um deles. 
Tabela 1

Distribuição de Frequência (\%) e Valor Médio do Índice de Partidarismo nos Estados

\begin{tabular}{lllllll}
\hline Estado & \multicolumn{1}{l}{ Índice de partidarismo } & \multicolumn{3}{l}{} & Total $(\mathbf{N})$ & $\begin{array}{l}\text { Valor médio do índice } \\
\text { de partidarismo }\end{array}$ \\
\cline { 2 - 4 } & $\mathbf{0}$ & $\mathbf{1}$ & $\mathbf{2}$ & $\mathbf{3}$ & & \\
\hline RS & 4,3 & 26,1 & 39,1 & 30,5 & 46 & 1,96 \\
\hline SC & 8,3 & 25,0 & 30,6 & 36,1 & 36 & 1,94 \\
\hline SP & 26,3 & 22,4 & 18,4 & 32,9 & 76 & 1,60 \\
\hline PE & 21,1 & 31,6 & 21,1 & 26,3 & 38 & 1,53 \\
\hline PA & 23,7 & 34,2 & 18,4 & 23,7 & 38 & 1,42 \\
\hline BA & 34,6 & 19,2 & 21,2 & 25,0 & 52 & 1,37 \\
\hline MG & 29,5 & 34,4 & 19,7 & 16,4 & 61 & 1,23 \\
\hline CE & 35,0 & 30,0 & 17,5 & 17,5 & 40 & 1,18 \\
\hline RJ & 43,4 & 20,8 & 20,8 & 15,1 & 53 & 1,08 \\
\hline GO & 25,8 & 45,2 & 25,8 & 3,2 & 31 & 1,06 \\
\hline MT & 29,4 & 41,2 & 23,5 & 5,9 & 17 & 1,06 \\
\hline TO & 47,3 & 21,1 & 26,3 & 5,3 & 19 & 0,89 \\
\hline Total (N) & 137 & 142 & 116 & 112 & 507 & 1,40 \\
\hline
\end{tabular}

Fonte: Banco de dados Projeto “Trajetórias, perfis e padrões de interação em doze estados da federação".

A variação do índice e o contraste entre os extremos da Tabela 1 são expressivos. No Rio Grande do Sul, 30,4\% dos entrevistados revelaram baixo perfil partidário - posições 0 e 1 . Em Santa Catarina foram 33,3\% e em São Paulo 48,7\%. Já nos estados do Rio de Janeiro, Goiás, Tocantins e do Mato Grosso as posiçóes 0 e 1 foram ocupadas por $64,2 \%, 71,0 \%, 70,6 \%$ e $68,4 \%$ dos legisladores respectivamente.

\section{A estabilidade da competição política nos estados}

A discussão sobre a "consolidação estrutural" dos sistemas partidários remonta a Sartori. O conceito, para o autor, atenta para o "impacto imobilizador das estruturas" (1976, p. 294). De maneira simplificada, um sistema estruturado constitui-se quando o eleitor, ao votar, orienta-se por um vínculo de lealdade e por uma imagem abstrata que faz dos partidos. O sistema passa a ser percebido, então, como "um sistema natural de canalização da sociedade política" (Sartori, 1996, p. 51).

Não parece haver dúvidas quanto ao fato de que sistemas partidários "consolidados" tendem a gerar melhores resultados do que aqueles que não atingem tal condição. $\mathrm{O}$ jogo político torna-se mais estável, menos permeável ao surgimento de outsiders e mais inteligível para o eleitor, ampliando, em decorrência, as chances de que ele possa exercer algum controle sobre os representantes eleitos. ${ }^{3}$

O problema passa a ser como mensurar o grau de consolidação ou institucionalização de um sistema partidário. Sartori não se detém neste ponto, limitando-se a dizer que "os partidos de massas são um bom indicador de um sistema de partidos estruturado” (1976, p. 295). ${ }^{4}$ Ao fazer essa opção, Sartori "condena" os sistemas partidários das novas democracias a um estado de "não consolidação". Essa questão tem sido lembrada e discutida em trabalhos mais recentes(Mainwaring e Scully, 1995; Mainwaring e Torcal, 2005 e Mainwaring e Zoco, 2007), que procuram desenvolver um referencial 
analítico para o estudo dos sistemas partidários nas democracias da "terceira onda". A ideia básica é de que seria possível trabalhar o conceito de institucionalização como um contínuo. ${ }^{5} \mathrm{Na}$ formulação inicial do problema, Mainwaring e Scully optaram por trabalhar com quatro dimensōes da institucionalização. Já no artigo de 2005, Mainwaring e Torcal limitam-se a trabalhar com duas delas: a estabilidade na competição eleitoral (medida por meio da volatilidade) e a profundidade das raízes partidárias na sociedade. ${ }^{6}$

A noção de institucionalização, por outro lado, ajuda a entender a dinâmica dos sistemas partidários nas novas democracias, com a ressalva de que não se deve pressupor um processo de caráter teleológico - cuja meta seria "alcançar" o modelo europeu - e muito menos irreversível, como o mostra a experiência recente da Venezuela. ${ }^{7}$ De modo mais específico, aqui interessa abordar um aspecto da institucionalização dos sistemas partidários: sua capacidade de desenvolver um padrão estável de competição política.

Visto sob este ângulo o sistema partidário brasileiro tem apresentado uma evolução positiva. Ainda que a fragmentação mantenha-se alta e o nível de identificação partidária, baixo, não se registram mais partidos que desaparecem da noite para o dia depois de terem sido usados pelos políticos. As quatro maiores legendas nacionais - PT, PSDB, PMDB e DEM - controlam desde 1994 no mínimo $60 \%$ da Câmara e $70 \%$ do Senado. Nas eleições presidenciais, também desde 1994, observa-se um padrão de disputa bipartidária, e no Congresso os partidos que formam o "núcleo duro" dos dois blocos em disputa não compartilham as mesmas coalizôes (Melo, 2007). ${ }^{8}$

Mas o quadro muda quando o foco se desloca para os estados. Países federalistas, em especial aqueles cujas unidades subnacionais são dotadas de elevado nível de autonomia, costumam apresentar dinâmicas políticas regionalmente diferenciadas, com impacto sobre a competição nacional. Nestes casos, a eleição regional, ainda que vinculada à disputa nacional, possui importância em si mesma, seja para o eleitor, que pode escolher candidatos de diferentes partidos nos dois níveis; seja para os partidos, que podem estabelecer coligaçôes distintas; seja para os políticos individualmente, que têm sua carreira assentada em vínculos de ordem local.

No caso brasileiro, tal tendência foi acentuada pelo fato de que a matriz originária do atual sistema partidário - o bipartidarismo que emerge das urnas em 1982 - viu-se completamente modificada nos anos seguintes, ao contrário do que aconteceu com o sistema inaugurado em 1945. Naquele período ocorreram mudanças na correlação de forças entre os três grandes partidos, mas não se verificou a emergência de legendas desafiantes. Atualmente, a quebra da matriz foi dramaticamente ilustrada pela implosão do PMDB na Constituinte (Melo, 2004), em um processo que abriu espaço a uma caótica reacomodação das elites regionais e contribuiu para uma expressiva diferenciação no interior do sistema partidário nacional. ${ }^{9}$ Como resultado, os sistemas partidários estaduais passaram por processos distintos a depender da força local dos grandes partidos nacionais e do padrão de interação estabelecido entre os competidores.

Se para o período democrático iniciado em 1945 fazia sentido analisar tais subsistemas, como o demonstrou Lima Jr. (1983), hoje isso é ainda mais claro e uma série de autores têm se dedicado a esta tarefa. Ferreira, Batista e Stabile (2008) analisaram a oferta partidária nos estados brasileiros tendo em conta a idade dos partidos, a votação recebida nos diversos níveis e alguns elementos dos sistemas estaduais. Rennó, Peres e Ricci (2008) procuraram explicar a variação encontrada nos índices de volatilidade para as eleiçōes da Câmara dos Deputados nos estados. Epstein (2009) argumentou ser possível distinguir quatro diferentes padrōes de competição entre os estados brasileiros (fragmentado, instável competitivo, estável competitivo e hegemônico) e apresentou como variável explicativa mais importante o grau em que os partidos, nos estados, aderem a estratégias clientelísticas na busca de vínculos com o eleitor. Por fim, Bohn e Paiva (2009) analisaram a tendência apresentada pelos índices de volatilidade nos estados considerando-se todos os tipos de pleito.

Para os objetivos deste texto interessa distinguir os doze estados analisados no que se refere ao grau de estabilidade/instabilidade da competição eleitoral, uma vez que se supõe haver alguma re- 
Tabela 2

Índice de Instabilidade da Competição Eleitoral Estadual

\begin{tabular}{lllllll}
\hline Estado & Volatilidade & \multicolumn{1}{c}{ Câmara } & Gov. Estadual & $\begin{array}{l}\text { Migrantes } \\
\text { (\%) }\end{array}$ & $\begin{array}{l}\text { Dif. Vot. } \\
\text { Gov./Partido }\end{array}$ & $\begin{array}{l}\text { Índice de } \\
\text { instabilidade }\end{array}$ \\
\cline { 2 - 5 } & Assembleia & 34,8 & 64,57 & 45,8 & 36,8 & 2,18 \\
\hline MT & 36,2 & 35,1 & 58,25 & 37,0 & 27,7 & 1,92 \\
\hline RJ & 34,2 & 42,5 & 45,33 & 43,8 & 26,6 & 1,90 \\
\hline PE & 31,9 & 32 & 50,06 & 33,8 & 32,6 & 1,82 \\
\hline CE & 33,3 & 34,7 & 51,90 & 28,0 & 23,5 & 1,75 \\
\hline MG & 33 & 30,7 & 51,39 & 29,2 & 31,0 & 1,75 \\
\hline BA & 31,1 & 29,3 & 40,13 & 32,5 & 27,4 & 1,60 \\
\hline PA & 31,2 & 28,5 & 55,23 & 18,0 & 21,9 & 1,55 \\
\hline GO & 32,7 & 32,4 & 39,16 & 21,8 & 23,4 & 1,50 \\
\hline SP & 22,4 & 25,3 & 35,89 & 25,9 & 15,7 & 1,25 \\
\hline RS & 18,5 & 18,6 & 35,15 & 8,6 & 20,3 & 1,01 \\
\hline SC & 18,0 & 17,4 & 32,53 & 11,5 & 18,5 & 0,98 \\
\hline
\end{tabular}

Fontes: Banco de dados Projeto “Trajetórias, perfis e padrões de interação em doze estados da federação"; Melo (2004); Melo e Miranda (2006).

lação entre esta variável e o perfil mais ou menos partidário revelado pelos deputados nas entrevistas realizadas. Nos estados onde os partidos estruturam de forma mais clara a competição, gerando ganhos de estabilidade, sua importância será mais destacada, se não para a escolha do eleitor (isso é algo que aqui não poderá ser verificado), certamente para a constituição das carreiras políticas. Não se pretende neste estudo estabelecer, tal como faz Epstein (2009), diferentes padrões de competição, mas apenas localizar os estados em um contínuo referente ao quesito estabilidade. ${ }^{10}$ Por outro lado, acredita-se que o grau de estabilidade da competição eleitoral, embora represente um aspecto crucial da institucionalização ou "consolidação estrutural" dos sistemas partidários, não necessariamente esgota a discussão a esse respeito.

Para classificar os sistemas partidários em função do grau de estabilidade na competição eleitoral foram definidos cinco indicadores. Tradicionalmente utilizado na discussão sobre institucionalização, o índice de volatilidade responde pelos três primei- ros, com base nas eleições para as Assembleias Legislativas, a Câmara dos Deputados e os governos estaduais entre 1982 e 2006 . Como já ressaltado pela literatura, observa-se grande variação entre as unidades da federação. Para as três medidas, o valor encontrado para o estado com os menores índices, no caso Santa Catarina, é cerca da metade daquele verificado nos estados onde o sistema partidário se mostra mais volátil - Mato Grosso nas eleições para Assembleias e governos e Tocantins para a Câmara dos Deputados. Na Tabela 2 são apresentados os valores médios para o período.

O quarto indicador é o percentual de deputados eleitos para a Câmara que mudou de partido entre 1982 e 2006. Foram considerados apenas os titulares. A suposição é a de que uma alta taxa de deputados migrantes aumenta a instabilidade dos resultados eleitorais, uma vez que o deputado que troca de partido leva consigo parcela de seu eleitorado. Não é por outra razão que, como mostraram Melo (2004) e Rennó, Peres e Ricci (2009), a incidência das migrações encontra-se associada 
ao índice de volatilidade nos estados. Neste caso, a variação é ainda mais expressiva do que para os índices de volatilidade, como a observação da tabela evidencia.

A diferença em termos percentuais entre a votação, no primeiro turno, do governo eleito e de seu partido para a Assembleia Legislativa fornece o quinto indicador. O suposto é de que nos estados onde tais votaçôes se encontram mais próximas os partidos são referenciais mais fortes no momento da escolha eleitoral. Os valores apresentados referem-se à média para o período considerado. Novamente a diferença é significativa: a distância média entre as votaçōes para o governador e seu partido é de 15,7\% em São Paulo e de 36,85\% no Mato Grosso.

Como se pode perceber pela Tabela 2, os indicadores estão fortemente correlacionados. Para qualquer par de indicadores a relação, medida pelo coeficiente de Pearson, é de no mínimo 0,606, significativo a 0,01 . O passo seguinte foi estabelecer um índice que permitisse a comparação entre os estados no modelo a ser utilizado. Para tanto, o procedimento foi simples: os valores obtidos em cada célula foram normalizados e somados, resultando em um índice com variação de 0 a 5 . Dessa forma, quanto mais elevados os valores obtidos pelo estado nos indicadores utilizados, mais próximo de 5 ele estará situado, o que significa que menos estável terá sido a competição eleitoral entre os anos de 1982 e 2006. O resultado expresso na última coluna da Tabela 2 remete, portanto, a um indice de instabilidade da competição eleitoral. Em um extremo da tabela encontram-se os estados onde a competição eleitoral apresenta maior estabilidade: Santa Catarina, Rio Grande do Sul e São Paulo. Por outro lado, no Mato Grosso, Tocantins e Rio de Janeiro o cenário revela-se mais volátil.

\section{Quem são os deputados partidários?}

Nesta seção serão apresentadas as hipóteses formuladas com o objetivo de discutir a relação entre determinadas características individuais dos legisladores entrevistados e seu grau de partidarismo.

A primeira hipótese refere-se ao tempo de filiação. Em trabalho sobre as migrações partidárias no Brasil, mostrei (Melo, 2004) que deputados com mais de oito anos de filiação a uma legenda possuíam quatro vezes menos chance de mudar de partido do que aqueles filiados a menos de quatro anos. $\mathrm{O}$ argumento aqui segue a mesma direção: maior tempo de permanência do deputado em um partido indica a existência de incentivos, coletivos ou seletivos (Panebianco, 1988), preciosos para a carreira política. A hipótese, portanto, é de que deputados com maior tempo de filiação apresentem perfil mais partidário. Os dados sobre filiação foram obtidos diretamente com os deputados. Dos 513 deputados entrevistados, 22 (4,3\%) haviam se filiado a seu partido em 2007 - ano que foi realizada a pesquisa; outros $148(28,8 \%)$ filiaram-se entre 2003 e 2006; 93 (18,1\%) filiaram-se entre 1999 e 2002; 47 (9,2\%), entre 1995 e 1998, enquanto $189(36,8 \%)$ ingressaram em seu partido antes de $1995 .{ }^{11}$

A segunda hipótese refere-se à ideologia. A hipótese é de que deputados eleitos por partidos de esquerda apresentem perfil mais partidário. Seguindo meu argumento (Melo, 2004), duas razōes podem ser apontadas para isso. De um lado, é possível caracterizar os partidos de esquerda como organizações dotadas de orientação mais programática, em contraposição ao caráter mais nitidamente eleitoral dos partidos situados à direita do espectro político. ${ }^{12} \mathrm{O}$ maior peso conferido a questōes programáticas e ideológicas explicaria a existência de vínculos mais robustos entre tais partidos e seus representantes. Nos termos de Panebianco (1982), em partidos com essas características os incentivos de tipo coletivo mantêm sua importância, ao contrário do que ocorre em partidos "puramente" eleitorais, em que os incentivos seletivos são largamente dominantes, quando não únicos.

Uma segunda explicação abre espaço para um cálculo de ordem mais pragmática por parte dos deputados: a possibilidade de que os membros dos partidos de esquerda se beneficiem de estratégias eleitorais coletivas desenvolvidas por suas organizaçôes. No PT, o mais notório dos casos, a ênfase conferida à legenda sempre reduziu os custos de campanha e possibilitou a eleição de deputados com votação mais baixa do que a necessária nos demais partidos de porte médio e grande. Em menor grau, o racio- 
cínio vale para as seçōes do PDT no Rio de Janeiro e no Rio Grande do Sul. No PC do B, a opção pelo lançamento de apenas dois ou três candidatos em cada estado, geralmente em coligação com o PT, faz com que os escolhidos - e quase sempre são os mesmos, dado que a definição da lista é uma atribuição do comitê dirigente no estado - possuam melhores perspectivas de sucesso eleitoral que em qualquer outra legenda. Os deputados eleitos pela esquerda também podem contar com outro importante recurso eleitoral: os laços com os militantes oriundos dos movimentos sociais. Pode-se dizer, portanto, que para os políticos de esquerda a relação entre sucesso eleitoral e estrutura partidária é mais clara do que no caso dos que se perfilam ao centro e à direita.

Para operacionalizar o teste da hipótese os partidos foram classificados em um contínuo esquerda-direita com base em uma média obtida a partir de três questões contidas no questionário aplicado aos deputados. Tomando como base uma escala de 1 a 10, em que 1 representa a posição mais à esquerda e 10 a posição mais à direita, foi solicitado aos deputados que classificassem um conjunto de partidos que não o seu, que se autoclassificassem e que classificassem seu próprio partido ${ }^{13}$. Seguindo Castro, Nunes e Anastásia (2009), que trabalharam com os mesmos dados, foram considerados de esquerda os partidos cuja média obtida ficou entre 0 e 4 (PCdoB, PSOL, PT, PDT e PSB). Foram classificados como de centro aqueles situados entre 4,1 e 6,0 (PMDB, PSDB, PPS, PV, PSC, PTdoB, PHS, PSL, PMN, PRB e PSDC). À direita foram posicionados os que se situaram acima de 6,0 (PTB, PR, DEM, PP, PTN e PAN). Ao final o conjunto dos deputados eleitos por partidos classificados à esquerda abrangeu $27,7 \%$ do universo pesquisado, os eleitos pelo centro, $45,2 \%$, e aqueles cujo partido situava-se à direita, $26,7 \%$.

A terceira hipótese aventada é de que deputados com tendência a exercer o mandato sob uma ótica mais universalista, em contraposição àqueles de orientação mais particularista, tendem a apresentar perfil mais partidário. Na literatura especializada é comum encontrar a suposição de que o particularismo tende a prevalecer em contextos onde predomina o voto personalizado (Kitschelt, 2000), processo que poderia ser mitigado com a presença mais destacada dos partidos (Shugart, 2001). Ou seja, deputados que constroem seu mandato prioritariamente com base no atendimento de demandas específicas tendem a se apoiar mais em relações de caráter individual, dispensando, ou minimizando a importância da mediação partidária. De acordo com Linz (2002), aqueles que representam "interesses especiais" entram, com frequência, em conflito com seus líderes, mais preocupados com interesses de caráter universal.

Para a medida do grau de particularismo dos deputados foi adotado o índice utilizado por Castro, Nunes e Anastásia. Trabalhando com o mesmo questionário utilizado para este artigo, os autores chegaram a um índice somatório criado a partir das seguintes questões: (a) afirmação do deputado de que a função a que dá mais importância é "propor emendas ao orçamento estadual que beneficiem a sua região"; (b) frequência com que os deputados afirmam ter realizado, na atual legislatura, a atividade de "atender ou encaminhar pleitos de seus eleitores"; (c) frequência com que os deputados afirmam ter realizado, na atual legislatura, a atividade de "tratar, junto à burocracia, das demandas de prefeitos de sua região"; (d) frequência com que o deputado utiliza "visitas às suas bases eleitorais" como meio para informar seus eleitores sobre sua atuação parlamentar; (e) importância que o deputado dá a "conseguir recursos para a sua base eleitoral" na reeleição de um candidato à Assembléia Legislativa. ${ }^{14} \mathrm{O}$ índice construído variou de 2,67 a 20 pontos, com média de 14,77 e desvio padrão de 3,38 (Castro, Nunes e Anastásia, 2009, p. 978).

A quarta hipótese formulada foi a de que deputados mais progressistas tenderiam a apresentar perfil mais partidário, o que resulta, simplesmente, de uma derivação da antiga tese da sociologia política, segundo a qual contextos mais modernos associam-se à presença de partidos políticos, enquanto contextos mais tradicionais vinculam-se a relaçôes políticas de tipo personalista (Lipset e Rokan, 1967).

No questionário utilizado na pesquisa, os deputados foram convidados a se posicionar contra ou a favor de alguns temas polêmicos. Foram considerados progressistas os que se manifestaram 
contra a pena de morte, a favor da descriminalização do uso de drogas, da união civil de pessoas do mesmo sexo, do aborto como direito das mulheres e da proibição da venda de armas de fogo. Com base nestas questóes foi possível chegar a um índice de progressismo com variação de 0 a 5. Apenas 3,5\% dos deputados foram classificados na posição mais conservadora (0). Na posiçãao (1) ficaram $18,9 \%$, na (2) $27,3 \%$, na (3) $25,7 \%$, na (4) $16,6 \%$ e na posição mais progressista $8,0 \%$ dos entrevistados.

A quinta hipótese defende que deputados vinculados a religiōes mais conservadoras apresentarão perfil menos partidário. A intenção inicial era a de estabelecer um contraponto entre os deputados evangélicos e os demais. ${ }^{15}$ Segundo alguns autores (Pierucci, 1989; Prandi, 1992; Freston, 1993), é possível afirmar que os evangélicos possuem um perfil mais conservador que estaria associado, de acordo com Prandi (1992), a uma pregação - dirigida aos eleitores - segundo a qual é preciso se manter longe do terreno da política e de tudo o que ela representa e à percepção de que o que vale é a defesa dos interesses e dos valores defendidos pela Igreja (o que muitas vezes assume a forma de uma "candidatura oficial"). Nesse contexto, faz pouco sentido esperar que tais deputados se sintam vinculados aos partidos pelos quais foram eleitos, o que é perfeitamente coerente quando se observa a trajetória dos deputados evangélicos na Câmara dos Deputados. Como mostra Fernandes (2004), tais deputados distribuem-se pelas mais diversas legendas ao centro e à direita e trocam de partido com muita frequência.

No entanto, o pequeno número de deputados que declarou pertencer a igrejas evangélicas impossibilitou que se pudesse utilizar esse grupo como referência na discussão. A alternativa, pois, foi recorrer ao "outro lado" do espectro, uma vez que o questionário permitia distinguir os católicos próximos à teologia da libertação dos católicos carismáticos ou que se declararam conservadores. Um total de 146 entrevistados declarou-se católico progressista ( $28,5 \%$ do universo), o que permitiu utilizar este grupo como referência, contrapondo-o ao grupo composto pelos demais deputados católicos e pelos evangélicos.
Por fim, foi possível formular outras três hipóteses, segundo as quais deputados com perfil mais individualista tenderiam a: (1) pertencer a famílias com tradição política; (2) não possuir experiência legislativa; (3) apresentar maior nível de renda e não se dedicar exclusivamente à atividade legislativa. A primeira hipótese fundamenta-se na ideia de que no Brasil a existência de uma tradição política que passa de pai para filho ajusta-se melhor à visão de que os partidos são um instrumento a ser utilizado de acordo com a conveniência. Para operacionalizá-la foi utilizada a questão sobre a presença de familiares na política e agrupadas as respostas que apontavam a presença de pai/mãe de forma isolada ou associada a tio/avô. A segunda hipótese baseia-se na ideia de que o cenário legislativo brasileiro é distinto do cenário eleitoral no sentido de que, no primeiro, os partidos contam de forma mais efetiva e sem o seu concurso a busca dos objetivos dos deputados tende a se frustrar (Figueiredo e Limongi, 1999). A pergunta utilizada permitia separar os deputados de primeiro mandato dos demais. Para a última hipótese recorreu-se, novamente, aos estudos clássicos sobre os partidos que sustentam que os vínculos entre estes e seus membros tendem a ser mais fortes quanto menor a autonomia econômica dos segundos. Ainda que aqui não esteja se tratando de cidadãos "comuns" e sim de parte da elite brasileira, a intenção era verificar se as distinções existentes neste nível poderiam contribuir na explicação da variação no grau de partidarismo. Foram destacados do conjunto dos deputados aqueles que, ao mesmo tempo, ocuparam as duas maiores faixas de renda e declararam se dedicar a outras atividades além da legislativa, num total de 137 entrevistados (26,7\% do universo).

\section{Testando as hipóteses}

Para o teste das hipóteses utilizou-se um modelo de regressão logística multinomial. Diferente da regressão logística, esse modelo é recomendado quando a variável dependente, no caso o índice de partidarismo, não se restringe a duas categorias. Tampouco seria adequado o uso de uma regressão linear, visto que não existe um ordenamento natural entre as categorias da variável. O modelo mul- 
Tabela 3

Coeficiente de Regressão Multinomial para Partidarismo ${ }^{17}$

\begin{tabular}{|c|c|c|c|c|c|}
\hline \multirow[t]{2}{*}{ Índice de partidarismo } & \multirow[t]{2}{*}{ B } & \multirow[t]{2}{*}{ Sig. } & \multirow[t]{2}{*}{$\operatorname{Exp}(B)$} & \multicolumn{2}{|c|}{$\begin{array}{l}\text { Intervalo de confiança } \\
(95 \%)\end{array}$} \\
\hline & & & & Inferior & Superior \\
\hline \multicolumn{6}{|l|}{1} \\
\hline Intercept & $-0,435$ & 0,301 & - & - & - \\
\hline Estabilidade eleitoral & 0,466 & 0,130 & 1,594 & 0,872 & 2,912 \\
\hline Tempo de filiação & 1,135 & 0,002 & 3,112 & 1,506 & 6,431 \\
\hline Ideologia & 0,466 & 0,182 & 1,593 & 0,804 & 3,159 \\
\hline Particularismo & 0,431 & 0,098 & 1,539 & 0,923 & 2,566 \\
\hline Progressismo & $-0,179$ & 0,499 & 0,836 & 0,497 & 1,406 \\
\hline \multicolumn{6}{|l|}{2} \\
\hline Intercept & $-1,332$ & 0,000 & - & - & - \\
\hline Estabilidade eleitoral & 0,707 & 0,029 & 2,028 & 1,075 & 3,826 \\
\hline Tempo de filiação & 2,073 & 0,000 & 7,950 & 3,862 & 16,369 \\
\hline Ideologia & 0,701 & 0,053 & 2,016 & 0,991 & 4,103 \\
\hline Particularismo & 0,694 & 0,015 & 2,001 & 1,143 & 3,504 \\
\hline Progressismo & 0,081 & 0,781 & 1,084 & 0,614 & 1,914 \\
\hline \multicolumn{6}{|l|}{3} \\
\hline Intercept & $-3,012$ & 0,000 & - & - & - \\
\hline Estabilidade eleitoral & 0,973 & 0,006 & 2,646 & 1,318 & 5,310 \\
\hline Tempo de filiação & 2,748 & 0,000 & 15,616 & 7,167 & 34,002 \\
\hline Ideologia & 1,688 & 0,000 & 5,409 & 2,578 & 11,346 \\
\hline Particularismo & 0,672 & 0,041 & 1,959 & 1,029 & 3,730 \\
\hline Progressismo & 1,048 & 0,003 & 2,853 & 1,442 & 5,645 \\
\hline
\end{tabular}

Nota: Categoria de referência: 0 .

tinomial permite perceber como as categorias se comportam sob a influência dos fatores escolhidos como preditores.

No modelo apresentado a seguir, nem todas as variáveis independentes foram incluídas. As variáveis tradição familiar e experiência legislativa não mostraram correlação significativa com o índice de partidarismo. As hipóteses correspondentes foram, portanto, refutadas. A variável renda apresentou correlação significativa e no sentido esperado quando submetida a testes simples de correlação. Mas, uma vez introduzida no modelo de regressão a significância, desapareceu por completo.

Também não foi incluída no modelo final a variável religiāo. Ela apresentou correlação significativa com o índice de partidarismo - deputados que se declaram evangélicos, católicos conservadores ou carismáticos tendem a situar-se nas categorias 0 e
1 do índice de partidarismo, enquanto os católicos progressistas são encontrados com maior frequência nas categorias 2 e 3. Quando introduzida no modelo, o desempenho da variável é igualmente relevante. No entanto, o número de deputados sem religião ou cuja opção religiosa não podia ser facilmente classificada fez com que a quantidade de casos perdidos saltasse de 22 para 83. Por conta disso, optou-se por retirar a variável do modelo.

Dessa forma, o modelo final contou com cinco variáveis independentes: grau de estabilidade da competição eleitoral estadual, tempo de filiação, ideologia, particularismo e progressismo. Todas elas foram tratadas como dummies. No caso da competição eleitoral optou-se por separar os estados mais estáveis - Santa Catarina, Rio Grande do Sul e São Paulo (Tabela 2) - dos demais, dando-lhes o valor (1). ${ }^{16}$ Quanto ao tempo de filiação, os deputados 
foram divididos em dois grupos: os com filiação entre 2007 e 1995 (0) e aqueles com filiação anterior a este ultimo ano (1). Para o caso da ideologia, os deputados filiados a partidos de centro e direita foram classificados como (0) e os de esquerda como (1). No que se refere ao particularismo, os deputados situados acima da média $(14,67)$ obtida no índice de Castro, Nunes e Anastasia (2009) assumiram o valor (0). No caso do índice de progressismo, optou-se por agregar os deputados inicialmente classificados em 0,1 e 2, contrapondo-os ao grupo dos classificados em (3), (4) e (5). Os mais progressistas receberam o valor (1). Assim, espera-se que os resultados sejam positivos para todas as variáveis - deputados de perfil mais partidário terão mais chance de serem encontrados nos sistemas de maior estabilidade eleitoral e entre aqueles deputados com maior tempo de filiação, mais universalistas, eleitos por partidos de esquerda e de perfil mais progressista.

A Tabela 3 permite confirmar as previsōes. $\mathrm{O}$ modelo mostra que a variável tempo de filiação é a que apresenta melhor desempenho, mantendo valores significativos e no sentido esperado para as categorias (3), (2) e (1), quando comparadas à categoria de referência (0). Deputados de perfil mais partidário, categoria (3), possuem 15,6 vezes mais chance de estarem entre aqueles que possuem maior tempo de filiação (anterior a 1995) do que os deputados da categoria de referência, os de perfil menos partidário. Quando examinamos os deputados de categoria (2) a chance é 7,9 vezes maior, valor que cai para 3,1 quando a comparação é feita entre os deputados das categorias (1) e (0). ${ }^{18}$

A variável estabilidade eleitoral apresenta valores significativos e no sentido esperado para as categorias (3) e (2). Deputados mais partidários apresentam 2,6 vezes mais chance de serem encontrados nos sistemas partidários em que a competição eleitoral atingiu maior grau de estabilidade (SC, RS e SP) do que os deputados da categoria (0). Para os da categoria (2) a chance é um pouco menor: 2,0. Quando comparados os deputados de tipo (1) e (0), a diferença deixa de ser significativa.

Também a variável particularismo apresenta valores significativos e positivos para as duas mais altas categorias do índice de partidarismo. No en- tanto, o resultado é menos coerente do que o encontrado para a variável anterior, já que a chance de que deputados de tipo (2) sejam também mais universalistas - quando comparados aos de tipo (0) - é praticamente a mesma que a encontrada quando são analisados os deputados de tipo (3) em torno de 2,0. Ademais, pode-se observar que os valores encontrados para a categoria (2) são pouco mais significativos que aqueles observados para a categoria (3).

As variáveis ideologia e progressismo só apresentam resultado significativo quando são comparadas as categorias (3) e (0) do índice de partidarismo. Deputados de perfil mais partidário possuem 5,4 vezes mais chances de pertencer a partidos de esquerda e 2,8 vezes mais de estarem entre aqueles que professam valores mais progressistas. ${ }^{19}$ Quando se analisa os deputados da categoria (2), a variável ideologia ainda mantém-se significativa a 0,1 , enquanto o progressismo deixa de possuir qualquer relação com a variável dependente.

\section{Conclusão}

No Brasil convivem deputados com trajetória claramente partidária e outros para os quais o partido é um instrumento a ser utilizado de acordo com a circunstância. Este texto procurou explorar esta diferenciação e, dentro de seus limites, explicá-la.

Como ponto de partida foi utilizado um questionário aplicado a deputados eleitos em $2006 \mathrm{em}$ assembleias de doze estados brasileiros. Com base nas respostas obtidas a algumas das questões foi elaborado um índice de partidarismo.

Com o objetivo de explicar a variação observada no índice, um conjunto de hipóteses foi formulado e cinco delas puderam ser corroboradas. Pelos testes realizados, pode-se dizer que existe uma relação de reforço mútuo entre o tempo de filiação e a importância que o deputado confere ao partido. Da mesma forma, é possível afirmar que os deputados estaduais tendem a apresentar um perfil mais partidário nos estados com maior estabilidade na competição eleitoral. Trata-se de uma dimensão crucial do grau de institucionalização dos sistemas partidários. Em outras palavras, ali onde a interação 
entre os partidos apresenta padrão mais definido e um papel de maior relevo na competição política, pode-se dizer que os deputados the atribuem maior importância.

De forma um pouco menos consistente do que para a variável anterior, deputados que apresentam um mandato mais universalista tendem a apresentar um perfil mais partidário. $\mathrm{O}$ mesmo pode ser dito dos deputados eleitos por partidos de esquerda, mas neste caso a relação mostra-se mais frágil - o que pode indicar, voltando aos sistemas partidários, que o desempenho destes últimos no modelo, aqui medido pela estabilidade da competição eleitoral, não parece depender da presença de partidos de esquerda. Por fim, deputados que expressaram opiniōes mais progressistas sobre temas polêmicos (contra a pena de morte, a favor da descriminalização do uso de drogas, da união civil de pessoas do mesmo sexo, do aborto como direito das mulheres e da proibição da venda de armas de fogo) também se revelaram menos individualistas e mais partidários.

Os achados deste texto confirmam algumas hipóteses de caráter mais geral presentes na literatura dentro de limites evidentes. Em primeiro lugar, como já ressaltado, a pesquisa se refere apenas a alguns estados e não podem ser generalizadas ao conjunto dos deputados no país. Em segundo, o estudo abrange apenas uma legislatura e, nesse sentido, deve ser visto como uma análise exploratória. Os estudos sobre os legislativos subnacionais no Brasil estão apenas engatinhando, e este caso não representa uma exceção. Certamente conclusões mais robustas sobre o tema aqui tratado dependem da existência de séries históricas, algo que, evidentemente, ainda não possuímos.

\section{Notas}

1 Agradeço aos demais coordenadores do projeto, as professoras Fátima Anastasia, Magna Inácio e Mônica Mata Machado de Castro pela utilização dos dados. A pesquisa entrevistou 513 de um total de 624 deputados eleitos em 2006 para as assembleias dos referidos estados. O trabalho de campo foi realizado entre outubro de 2007 e março de 2008. Envolveram-se nas entrevistas os seguintes pesquisadores, estudantes da graduação em Ciências Sociais ou da pós-graduação em Ciência Política na UFMG: Alessandra Costa, Breno Cypriano, Carlos Augusto Mello Machado, Catherine Kelly Ornelas, Cláudio Lobenwein Resende, Daniela Paiva de Almeida Pacheco, Deivison Souza Cruz, Diogo César Pereira, Felipe Nunes dos Santos, Geralda Luiza de Miranda, Helga do Nascimento de Almeira, Ivânia Moraes, Juliana Jardim Pereira, Lucas Rodrigues Cunha, Luciana da C. Farias Santana, Marina Brito Pinheiro, Marta Mendes da Rocha, Maurício de Moura Marques Jr, Paulo Magalhães Araújo, Poliana Régia da Silva, Raquel Novais Reher, Renato Francisquini, Roberto Luiz Goulart Alves, Ronaldo Teodoro, Sandro Amadeu Cerveira e Thiago Rodrigues Silame. A pesquisa contou com financiamento da Fapemig e do CNPq. Beneficiou-se, ainda, de uma cooperação internacional com a Universidade de Salamanca (Espanha) financiada pela Capes.

2 São necessários ainda mais alguns agradecimentos. $\mathrm{O}$ primeiro é dirigido aos dois pareceristas anônimos pelas sugestōes apresentadas. O segundo, a Ernesto Amaral, colega do DCP/UFMG. Sem a sua ajuda o tratamento dos dados aqui efetuado não teria sido possível. É evidente que os problemas que ainda assim persistirem são de minha inteira responsabilidade. $\mathrm{O}$ terceiro, aos bolsistas de iniciação científica Leôncio Caetano de Farias, Ana Clara Fernandes Cavalcanti e Matheus Almeida, que auxiliaram na sistematização dos dados referentes aos sistemas partidários estaduais.

3 Evidentemente, há que se lidar com o problema da mudança. Ainda que Sartori não dê maior importância ao ponto, sistemas "consolidados" devem também apresentar capacidade de se adaptar a mudanças no ambiente externo, sob o risco de quebra (Cavarozzi e Casullo, 2003; Levitsky, 2005). A referência remete a um dos critérios definidos por Huntington (1975) ao discutir a institucionalização: a disjuntiva adaptabilidade/rigidez. Para o autor quanto mais rígido, menos institucionalizado é o sistema. O próprio Sartori, depois de apontar a proximidade entre os dois conceitos - consolidação estrutural e institucionalização -, ressalta a diferença a esse respeito, mas não a discute, limitando-se a dizer que seu conceito é "mais simples e menos ambicioso" que o de Huntington. Para os objetivos deste texto, na medida em que interessa aqui o requisito da estabilidade, os dois conceitos serão tratados do mesmo modo, como faz a literatura recente, ou seja, de forma intercambiável.

4 Tal formulação, constante no clássico Partidos e sistemas partidários, é menos abrangente do que a utilizada em Engenharia constitucional: afinal, nos Estados Uni- 
dos a existência de um "sistema natural de canalização" prescindiu da emergência de partidos de massa.

5 Discute-se bastante a utilização ou não da noção de contínuos na análise de sistemas. O próprio Sartori (1976) chama a atenção para alguns problemas na aplicação de tal ferramenta. Foge aos objetivos deste texto discutir essa questão, mas cabe ressaltar que a alternativa sartoriana - a rígida distinção entre sistemas consolidados e não consolidados - também não consegue resolver de forma satisfatória o problema da mudança e da passagem de um estado a outro.

6 Além destas, o trabalho inicial propunha que se levasse em conta a legitimidade conferida pelos atores políticos aos partidos e a prevalência das organizações partidárias sobre os interesses dos líderes.

7 Neste país o sistema partidário foi destruído poucos anos depois de ser apontado como altamente institucionalizado. Isso motivou Mainwaring e Torçal (2005) a reconhecerem de forma explícita aos problemas aqui discutidos. Novamente, é possível o retorno à disjuntiva adaptabilidade/rigidez, dando razão a Huntington "contra" Sartori - a débâcle venezuelana é um claro exemplo de um sistema cujos partidos se tornaram rígidos por demais, incapazes de responder às mudanças de caráter exógeno em curso no país desde os anos de 1980 (Anastásia, Melo e Santos, 2004).

8 PT, PSB e PCdoB, de um lado, e PSDB e DEM, de outro, estabelecem blocos distintos no Congresso, enquanto PMDB, PTB e PP oscilam entre os dois.

9 Um sistema partidário não pode ser confundido com um ajuntamento de partidos. Para que se possa falar de um sistema partidário é preciso que exista um conjunto de interações resultantes da competição entre os seus membros (Sartori, 1976). Em tal situação, os partidos não são o sistema e não podem mover-se à vontade porque se encontram constrangidos por suas interaçōes com os demais competidores (Mair e Bardi, 2008). Nesse sentido, para o caso brasileiro, seria mais apropriado falar em sistema partidário para o Rio Grande do Sul, Santa Catarina ou São Paulo, do que para Roraima, Rondônia ou Alagoas, estados onde mais da metade dos deputados eleitos para a Câmara entre 1982 e 2006 mudou de partido e a volatilidade média ultrapassou a assombrosa marca de 45 pontos.

10 O desafio de se chegar a padrōes de competição para os estados brasileiros é tão estimulante quanto complexo. Basta verificar como um dos padrões definidos por Epstein, com base nos dados de 1994 a 2002, deixou de existir após os resultados das eleições de 2006 e 2010. Segundo o autor, Bahia e Ceará seriam os mais claros exemplos de sistemas hegemônicos, nos quais um partido ficaria "com a parte do leão". As vitórias do PT e PSB trataram de modificar drasticamente a situação.

11 Apenas 14 deputados não responderam à questão.

12 A este respeito ver Gunther e Diamond (2003). Na tipologia proposta pelos autores, mesmo entre os partidos eleitoralistas, seria possível distinguir entre os de tipo catch all, os de tipo programático e os personalistas. Os segundos guardariam diversas semelhanças com os partidos de massa "clássicos". Wolinetz (2002), por sua vez, propõe uma série de critérios para distinguir entre partidos de tipo policy seeker, office seeker e vote seeker.

13 Tal procedimento tem sido utilizado pela equipe de pesquisadores responsáveis pela condução do projeto "Elites Parlamentares da América Latina" (PELA). A diferença aqui se encontra no aproveitamento da questão em que os deputados classificam os outros partidos que não o seu. No PELA, a posição ideológica dos partidos é obtida com base nas duas outras perguntas do survey (para o Projeto Elites, ver Alcántara, 2006). A mudança justifica-se porque no Brasil há tendência dos deputados pertencentes aos partidos conservadores de se posicionar ao centro, tendência "corrigida" pela referida questão. Melo e Nunes (2009) utilizaram as mesmas perguntas em uma comparação entre os deputados federais brasileiros e os chilenos.

$14 \mathrm{Na}$ primeira questão foram atribuídos quatro pontos ao deputado se ele afirmou dar importância "em primeiro lugar" a essa função, dois pontos se afirmou "em segundo lugar" e zero se não citou essa função entre as duas mais importantes. Para a segunda e a terceira questóes, utilizou-se a seguinte escala: muitas vezes, algumas vezes, poucas vezes ou nunca, e os números de zero a quatro foram atribuídos aos deputados de acordo com o grau crescente em sua resposta sobre a frequência das atividades. Na quarta questão os valores de zero a quatro foram atribuídos de acordo com a ordenação, feita pelos deputados, de um conjunto de cinco itens alternativos. Por fim, na última questão os pontos de zero a quatro foram atribuídos aos deputados de acordo com uma escala de resposta que variava de "nunca" a "frequentemente".

$15 \mathrm{O}$ total de 44 deputados declararam não possuir religião.

$16 \mathrm{Na}$ Tabela 2 chegou-se a um índice de instabilidade eleitoral. Aqui no modelo, como a expectativa era de uma relação positiva entre o índice de partidarismo e a estabilidade eleitoral - deputados mais partidários 
apresentando maior chance de serem encontrados nos estados onde a competição houvesse se mostrado mais estável - optou-se por conferir o valor (0) aos estados mais instáveis.

17 O modelo de regressão adotado não permite que o coeficiente de determinação, R2, seja calculado da mesma forma como em uma regressão de tipo linear. Um dos substitutos possíveis é o índice de Cox and Snell que, no caso em questão, atinge o valor de 0,346 - o valor 1 significaria que $100 \%$ da variação do fenômeno analisado seria explicada pelas variáveis independentes.

18 Os resultados são praticamente os mesmos quando se substitui a dummy tempo de filiação por uma variável com cinco categorias - 2007, 2003-2006, 20021999, 1995-1998, antes de 1995.

19 A substituição da variável ideologia por outra, na qual os deputados do PT são destacados dos demais, produz resultados semelhantes.

\section{BIBLIOGRAFIA}

AMES, Barry. (2003), Os entraves da democracia no Brasil. São Paulo, FGV.

ALCÁNTARA, Manuel (org.). (2006), Políticos y politica en América Latina. Madri, Fundación Carolina/Siglo XXI.

ANASTASIA, Fátima; MELO, Carlos \& SANTOS, Fabiano. (2004), Governabilidade e representação política na América do Sul. São Paulo, Konrad-Adenauer/Editora da Unesp.

AMORIM NETO, Otávio. (2000), "Gabinetes presidenciais, ciclos eleitorais e disciplina legislativa no Brasil". Dados - Revista de Ciências Sociais, 43 (3): 479-520.

BOHN, Simone \& PAIVA, Denise. (2009) "A volatilidade eleitoral nos estados: sistema partidário e democracia no Brasil”. Revista de Sociologia e Politica, 17 (33): 187-208.

CASTRO, Mônica Mata Machado; NUNES, Felipe \& ANASTASIA, Fátima. (2009), "Determinantes do comportamento particularista de legisladores estaduais brasileiros”. Dados - Revista de Ciências Sociais, 52 (4): 961-1001.

CAMPOS, Mauro Macedo. (2009), “Democracia, partidos e eleições: os custos do sistema partidário-eleitoral no Brasil”. Belo Horizontes, tese de doutorado, Ciência Política, UFMG.
CAVAROZZI, Marcelo \& CASULLO, Esperanza. (2003), "Los partidos politicos en América Latina hoy: consolidación o crisis?", in Cavarozzi e Medina (orgs.), El asedio a la política: los partidos latinoamericanos en la era neoliberal, Rosário, Homo Sapiens.

EPSTEIN, Daniel. (2009), "Clientelism versus ideology: problems of party development in Brazil". Party Politics, 15 (3): 335-355.

FERNANDES, Evandro Marcelo Alves. (2004), Protestantes e politica no Brasil: o perfil da atuação protestante na câmara dos deputados na década de 90. Belo Horizonte, dissertação de mestrado, Ciência Política, UFMG.

FERREIRA, Denise; BATISTA, Carlos \& STABILE, Max. (2008), "A evolução do sistema partidário brasileiro: número de partidos e votação no plano subnacional". Opinião Pública, 14 (2): 432-453.

FIGUEIREDO, Argelina \& LIMONGI, Fernando. (1999). Executivo e legislativo na nova ordem constitucional. Rio de Janeiro, FGV/Fapesp.

. (2002). "Incentivos eleitorais, partidos e política orçamentária”. Dados, 45 (2): 303344.

FRESTON, Paul. (1993), Protestantes e politica no Brasil: da constituinte ao impeachment. Campinas, tese de doutorado, Sociologia, Unicamp.

GUNTHER, Richard \& DIAMOND, Larry. (2003), "Species of political parties: a new tipology”. Party Politics, 9 (2): 167-199.

HUNTINGTON, Samuel. (1975), A ordem politica nas sociedades em mudança. São Paulo, Edusp.

INACIO, Magna. (2006). Presidencialismo de coalizão e sucesso presidencial no Brasil. Belo Horizonte, tese de doutorado, Sociologia e Política, UFMG.

KITSCHELT, Herbert. (2000), "Linkages between citizens and politicians in democratic polities". Comparative Political Studies, 33 (6-7): 145-172.

LEVITSKY, Steven. (2005), La transformación del justicialismo: del partido sindical al partido clientelista. Buenos Aires, Siglo XXI.

LIMA JR., Olavo Brasil. (1983), Os partidos politicos brasileiros: a experiência federal e regional: 1945-1964. Rio de Janeiro, Graal. 
LINZ, Juan. (2002), "Parties in contemprary democracies: problems and paradoxes", in $\mathrm{Ri}-$ chard Gunther, Jose Ramon-Montero e Juan Linz (orgs.), Political parties: old concepts and new challenges, Oxford, Oxford University Press.

LIPSET, Seymour \& ROKKAN, Stein. (1967), Party system and voter alignments. Nova York, The Free Press.

MAINWARING, Scott. (1991), "Políticos, partidos e sistemas eleitorais". Novos Estudos Cebrap, 29: 34-58.

(1993). "Democracia presidencialista multipartidária: o caso do Brasil". Lua Nova, 23/24: 21-73.

MAINWARING, S. \& SCULLY, Thimoty. (1995), Building democratic institutions: party systems in Latin America. Palo Alto, Stanford University Press.

MAINWARING, S. \& TORCAL, Mariano (2005). "Teoria e institucionalização dos sistemas partidários após a terceira onda de democratização". Opinião Pública, XI (2): 249-286.

MAINWARING, S. \& ZOCO, Edurne. (2007), "Political sequences and the stabilization of interparty competition: electoral volatility in old and new democracies". Party Politics, 13 (2): 155-178.

MAIR, Peter \& BARDI, Luciano. (2008), "The parameters of party systems". Party Politics, 14 (2): 147-166.

MANIN, Bernard. (1995), "Metamorfoses do governo representativo". RBCS, 29: 5-34.

MELO, Carlos Ranulfo. (2004), Retirando as cadeiras do lugar: migração partidária na Câmara dos Deputados (1985/2002). Belo Horizonte, Editora da UFMG.

. (2007). "Nem tanto ao mar, nem tanto a terra: elementos para uma análise do sistema partidário brasileiro", in Melo e Alcântara, A democracia brasileira: balanço e perspectivas para o século 21. Belo Horizonte, Editora da UFMG.

MELO, C. R. \& MIRANDA, Geralda. (2006), "Migração e partidos no governo Lula". Trabalho apresentado no V Encontro da ABCP, Belo Horizonte.
MELO, C. R. \& NUNES, Felipe (2009). "Ideologia e distância de preferências: uma comparação dos governos Lagos e Lula", in Rennó e Inácio (eds.), Legislativo brasileiro em perspectiva comparada. Belo Horizonte, Edditora da UFMG.

MIRANDA, Geralda. (2008), O comportamento dos partidos na Câmara dos Deputados e no Senado Federal (1991-2007). Belo Horizonte, tese de doutorado, Ciência Política, UFMG.

PANEBIANCO, Angelo. (1982). Modelos de partido. Madri, Alianza Editorial.

PIERUCCI, Antônio Flávio. (1989), "Representantes de Deus em Brasília: a bancada evangélica na constituinte", in Anpocs, Ciências Sociais Hoje, São Paulo, Vértice/Anpocs.PRANDI, Reginaldo. (1992), "Perto da magia, longe da política: derivaçōes do encantamento no mundo desencantado". Revista Novos Estudos Cebrap, 34: 81-91.

RENNÓ, Lucio; PERES, Paulo \& RICCI, Paolo. (2008), "A variação da volatilidade eleitoral no Brasil:um teste com as explicaçōes econômicas, políticas e sociais". Trabalho apresentado no VI Encontro da ABCP, Campinas.

SANTOS, Fabiano. (2003), O Poder Legislativo no presidencialismo de coalizão. Belo Horizonte, Editora da UFMG.

SARTORI, Giovanni. (1976), Partidos e sistemas partidários. Brasília, Editora da UnB.

. (1996), Engenharia Constitucional. Brasília, Editora da UnB.

SHUGART, Matthew. (2001), "Electoral 'efficiency' and the move to mixed-member systems". Electoral Studies, 20 (2): 103-121.

WOLINETZ, Steven. (2002), "Beyond the catch-all party: approaches to the study of parties and party organization in contemporary democracies", in Gunther, Monteiro e Linz (orgs.), Political parties: old concepts and new challenges. Oxford, Oxford of University Press. 


\section{INDIVIDUALISMO E PARTIDARISMO EM DOZE ESTADOS BRASILEIROS}

\section{Carlos Ranulfo Melo}

Palavras-chave: Individualismo; Partidarismo; Sistemas partidários estaduais; Assembleias legislativas.

$\mathrm{O}$ artigo procura explicar a variação na relação entre deputados e partidos em doze estados brasileiros. Tal variação é mensurada com o auxílio de um índice de partidarismo, construído com base em um conjunto de perguntas feitas aos representantes eleitos para as Assembleias Legislativas em 2006. A variação encontrada é explicada em dois níveis. $\mathrm{O}$ primeiro remete a uma das dimensões da institucionalização dos diversos sistemas partidários estaduais: a estabilidade da competição eleitoral. O segundo diz respeito às características dos deputados, tais como tempo de filiação, tipo de partido pelo qual foi eleito, grau de particularismo no exercício do mandato, grau de progressismo relativamente a temas contemporâneos e polêmicos.

\section{INDIVIDUALISM AND \\ PARTISANSHIP IN TWELVE \\ BRAZILIAN STATES}

\section{Carlos Ranulfo Melo}

Keywords: Individualism; Partisanship; State party systems; Legislative assemblies.

The article seeks to explain the variation of the relationship between legislators and parties in twelve Brazilian states. This variation is measured with the aid of an index of partisanship, built on a set of questions made to elected representatives of the Legislative Assemblies in 2006. The variation observed is explained in two levels. The first one refers to one dimension of the institutionalization of the various state party systems: the stability of electoral competition. The second one refers to features of the legislators such as period of affiliation, type of party by which he/ she was elected, degree of particularism in the exercise of mandate, the degree of progressive thought in relation to controversial, and contemporary issues.

\section{INDIVIDUALISME ET SECTARISME DANS DOUZE ÉTATS BRÉSILIENS}

\section{Carlos Ranulfo Melo}

Mots-clés: Individualisme; Sectarisme; Systèmes partidaires des états; Assemblées législatives.

L'article tente d'expliquer la variation dans la relation entre les députés et les partis dans douze états brésiliens. Cette variation est mesurée à l'aide d'un indice de sectarisme, construit sur la base d'un ensemble de questions posées aux représentants élus aux Assemblées Législatives en 2006. Elle s'explique sur deux niveaux. Le premier renvoie à l'une des dimensions de l'institutionnalisation des divers systèmes partidaires des états: la stabilité de la compétition électorale. Le second se rapporte aux caractéristiques des députés, tels le temps de filiation, le genre de parti politique par lequel il s'est élu, le degré de particularisme dans l'exercice du mandat, le degré de progressisme par rapport à des thèmes contemporrains et polémiques. 